J. Lake Sci. (湖泊科学), 2012, 24(1): 27-33

http: //www. jlakes. org. E-mail : jlakes@niglas.ac.cn

(C) 2012 by Journal of Lake Sciences

\title{
改革开放以来太湖流域工业企业布局演变"
}

\author{
袁 丰 $^{1}$, 宋正娜 ${ }^{2}$ \\ (1: 中国科学院南京地理与湖泊研究所, 南京 210008) \\ (2: 南京信息工程大学,南京 210044)
}

摘 要: 太湖流域快速工业化进程加剧了对该地区资源环境的扰动,不合理的工业布局是其重要原因. 本文采用经济普 查企业点位分布数据, 运用空间分析与有序 Probit 模型等方法, 定量分析改革开放以来, 太湖流域工业企业空间分布的格 局演变及其区位选择的驱动机理,并重点考察太湖环境保护对企业区位行为的影响. 结果表明, 在 2007 年太湖水危机事 件以前,上海以及太湖北部的苏锡常地区一直是该流域工业企业的主要集聚区域,但随着时间的推移呈现分散化趋势, 尤其以内资为主的小型污染企业呈现向宜兴等流域上游地区扩散是导致水危机暴发的一个重要原因. 而工业企业环境 保护意识淡薄和地方环境监管缺位是造成企业不合理分布的重要因素.

关键词: 空间格局;区位选择;污染型工业;科技型工业;太湖流域

\section{Spatial distribution of industrial firms in Taihu Basin since China's Reform and Opening-up}

\author{
YUAN Feng ${ }^{1} \&$ SONG Zhengna ${ }^{2}$ \\ (1: Nanjing Institute of Geography and Limnology, Chinese Academy of Sciences, Nanjing 210008, P. R. China) \\ (2: Nanjing University of Information Science and Technology, Nanjing 210044, P. R. China)
}

\begin{abstract}
The rapid industrialization of Taihu Basin increases the resources and environment perturbation in this region. One significant factor is the unreasonable locations of industry. To utilize the enterprise distribution data of economic census, using the spatial analysis and Ordered Probit model, this study analyzes the evolution of industrial enterprise spatial distribution and the mechanism of their locational action after the reform and opening-up policy, and focuses on how the protection of Taihu Basin might affect their locations. The results show that before the explosion of water crisis in Lake Taihu in 2007, the industrial enterprises in this region mainly agglomerate in Shanghai and Suzhou-Wuxi-Changzhou region(which is along the northern Lake Taihu). However, it takes on the tendency of decentralization over time, especially for those enterprises with pollution which have revealed an unreasonable spatial distribution, i. e. they changed their locations to upper reaches of Lake Taihu( such as Yixing, etc. ). This behaviour becomes an important factor which leads to the explosion of water crisis. Indifference to environmental protection awareness and omission of local environmental protection mechanism are the major reasons of unreasonable spatial distribution.
\end{abstract}

Keywords: Spatial pattern; location choice; pollution industry; science and technology industry; Taihu Basin

工业化进程影响下的工业分布格局演变是经济地理学的经典研究领域. 工业分布格局是微观企业区位 选择的空间表现,因而,区位理论是解释工业分布与地理集聚的理论基石 ${ }^{[1]}$.对企业区位的早期研究来自企 业选址的现实需求,虽然随着区位理论的发展,逐渐将交通成本、劳动力成本、原材料成本、税收、市场需求、 规模经济等因素纳人了区位分析 ${ }^{[2-5]}$,但是无论是成本学派还是市场学派,都将区位看成是企业生产函数的 一种要素投人,而忽视了社会和环境等因素的影响.事实上,合理的企业区位选择,应该是在综合考虑自然、 经济、社会等各种条件供给的基础上,对可行区位比较择优的结果,其最终目标就是要寻求区域内经济社会

* 中国科学院知识创新工程重要方向性项目 (KZCX2-YW-339)、国家自然科学基金重点项目(41130750) 和教育部人 文社会科学研究重大项目 (11JJDZH005) 联合资助. 2011-04-12 收稿;2011-08-26 收修改稿. 袁丰, 男,1982 年 生,博士, 助理研究员; E-mail :fyuan@ niglas. ac. cn. 
环境整体效益最大化 ${ }^{[6-7]}$. 但是实际上, 由于市场失灵、环境保护意识薄弱和监督机制缺位,一味追求地区经 济增长带来经济低效率和生态环境破坏等问题 ${ }^{[8-9]}$, 尤其是污染型工业的不合理分布是诱发水环境恶化、大 气污染、土壤污染、生物多样性减少等一系列生态环境破坏的重要原因 ${ }^{[10-12]}$, 这就需要政府加强对企业区位 选择的空间管制. 但是中国改革开放以后相当长的一段时间都是以经济增长、效率和竞争力为导向进行市 场改革 ${ }^{[13]}$,地方政府在实际操作中形成了“唯 GDP 论”,在大力发展经济的同时,忽视了对生态环境的保护.

在此背景下, 学界开始审视工业经济与生态环境间的辩证关系. 大量研究关注工业化过程的生态环境 负外部性, 重点分析工业结构演变以及不同类型工业对水环境、土壤和大气等的污染和破环 ${ }^{[14-16]}$, 比如研究 表明工业化在促进苏南农村经济腾飞的过程中, 也造成了“村村点火,户户冒烟” 的分散化的工业空间格局, 导致了大气污染、水质型缺水等环境问题 ${ }^{[17-18]}$; 也有部分学者研究了生态环境压力对工业空间调整和企业 绿色化行为等方面的影响 ${ }^{[19-20]}$, 但是总体而言, 现有研究主要从产业一区域角度分析工业空间格局的变动情 况, 较少研究从企业一区位这一更为微观的视角分析企业空间分布与环境间的关系. 为此, 本文以太湖流域 为研究案例, 运用企业点位分布数据, 通过分析工业企业空间分布格局的演变以及区位选择的影响机制, 重 点回答以下问题: 改革开放以来,太湖流域工业企业空间格局是如何演变的? 形成目前的空间格局背后的 作用机制是什么? 尤其是太湖环境保护对企业区位选择的影响如何? 考虑到污染型工业是影响太湖水环 境破坏的重要污染来源, 而低污染的科技型工业是沿湖地区产业结构调整的重要方向, 所以本文重点考察 这两类工业的区位选择及其空间分布情况.

太湖流域地跨苏浙皖沪三省一市, 流域面积 $36895 \mathrm{~km}^{2}$, 是长江三角洲地区的核心组成部分. 流域以太 湖为中心, 地势西高东低, 西部是上游山区独立水系, 东部为下游平原河网水系 ${ }^{[21]}$. 唐宋以来, 太湖流域一直 就是我国重要的经济中心, 尤其到了明清时期, 该地区率先进人早期工业化阶段, 纺织等手工业在全国占有 举足轻重的地位 ${ }^{[22-23]}$; 近代工业发轫于上海开埠后殖民工业、官办工业以及民族工业的发展 ${ }^{[24]}$; 改革开放以 后, 乡镇工业、外资企业和民营经济的蓬勃发展又推动该地区新一轮的经济增长 ${ }^{[25-27]}$, 至 2007 年, 太湖流域 以占不到全国 $0.4 \%$ 的陆地面积,集聚了全国 3\% 的人口和 $12 \%$ 的 GDP. 但是在经济发展和人口集聚过程 中, 也加剧了与资源环境之间的矛盾, 太湖水体污染和富营养化程度不断加深, 太湖水环境质量基本上每 10 年下降一个等级, 从 1970s 初的 II 类水体, 迅速退化为 1990s 中期的 IV 类水体 ${ }^{[28]}$. 虽然政府从 1998 年开始实 施包括“零点行动” 在内的一系列专项治理行动, 但是湖泊水质恶化的趋势并未得到根本遏制 ${ }^{[29]}$. 最终, 在 2007 年酿成了太湖水危机这样的重大环境悲剧. 其中, 日益累积的纺织印染、化工等工业污染, 尤其是污染 企业不合理的空间分布是导致该次环境大事件的重要成因之一 ${ }^{[30]}$. 因而, 该地区是研究工业空间格局与生 态环境关系的理想实证区域.

\section{1 研究方法与数据来源}

根据实证研究的需要, 本文采用核密度估计与有序 Probit 模型分别测度太湖流域工业企业空间格局演 变过程及其驱动机理.

\section{1 研究方法}

1.1 .1 核密度估计方法 为了更直观地表达不同年份太湖流域工业企业的空间分布及其变动情况, 本文运 用核密度估计的方法将点状的企业分布面状化. 核密度估计是通过考察区域中点密度的空间变化来研究点 的分布特征, 本文具体采用二次核函数来估计, 设 $p$ 处的密度为 $\lambda_{h}(p)$, 其估计值 $\hat{\lambda}_{h}(p)$ 则为:

$$
\hat{\lambda}_{h}(p)=\sum_{i=1}^{n} \frac{3}{\pi h^{2}}\left(1-\frac{\left(p-p_{i}\right)^{2}}{h^{2}}\right)^{2}
$$

式中, $p$ 为待估计点的位置; $p_{i}$ 为落在以 $p$ 为圆心, $h$ 为半径的圆形范围内的第 $i$ 个企业的位置; $h$ 代表步长, 即以 $p$ 为源点的曲面在空间上延展的宽度, $h$ 值的选择会影响到分布密度估计的平滑程度, 在具体应用中, $h$ 的取值有弹性,需要根据不同的 $h$ 值进行试验.

1.1 .2 有序 Probit 模型 由于难以获得太湖全流域生态环境数据资料, 研究中用距离太湖的远近来替代表 示太湖环境保护对企业区位选择的作用, 具体来说依据距离太湖的远近将太湖流域划分为三个圈层: 太湖 沿岸地区 (拥有太湖岸线的乡镇、街道)、临近太湖地区 (除沿岸地区以外的拥有太湖岸线的城市) 、远离太 
湖地区 (其他地区), 从而用企业落人的圈层来表示环境保护对该企业区位选择的影响. 对位于各个圈层中 的企业分别赋值 $0 、 1 、 2$, 数据越大表明企业选址考虑太湖保护的要求越多. 对于这种离散型的被解释变量, 不能采用最小二乘法进行回归,而需采用离散回归模型. 有序 Probit 模型是一种针对离散有序因变量的有效 模型, 可以很好地将企业、产业以及区位因素构人统一的模型加以考虑 ${ }^{[31]}$. 设定一个指代区位的潜在变量 $y_{i}^{*}$,可视作解释变量 $x_{i}$ 的函数,即:

$$
y^{*}=\beta^{\prime} X+\varepsilon
$$

式中, $\varepsilon$ 是随机变量, $\beta^{\prime}$ 是回归系数向量. 每个企业实际所在的区位 $y_{i}$ 可以直接通过观测得到, 即企业位于不 同圈层的区位 (取值为 $0 、 1 、 2$ ), 则 $y_{i}$ 和 $y_{i}^{*}$ 之间采用如下关系式:

$$
\text { 如果 } y_{i}^{*} \leqslant 0, y_{i}=0 \text {; 如果 } 0<y_{i}^{*} \leqslant \gamma, y_{i}=1 \text {; 如果 } \gamma<y_{i}^{*}, y_{i}=2
$$

式中, $\gamma$ 为待估计参变量,假设 $\varepsilon$ 遵从正态分布. 这样,工业企业选择不同圈层的概率为:

$$
\begin{gathered}
\operatorname{Pr}\left(y_{i}=0 \mid X, \beta^{\prime}, \gamma\right)=F\left(-\beta^{\prime} X\right) \\
\operatorname{Pr}\left(y_{i}=1 \mid X, \beta^{\prime}, \gamma\right)=F\left(\gamma-\beta^{\prime} X\right)-F\left(-\beta^{\prime} X\right) \\
\operatorname{Pr}\left(y_{i}=2 \mid X, \beta^{\prime}, \gamma\right)=1-F\left(\gamma-\beta^{\prime} X\right)
\end{gathered}
$$

式中, $F$ 是 $\varepsilon$ 的累积分布函数. 为了使所有的概率为正, 必须有 $\gamma>0 . \gamma$ 和回归系数 $\beta^{\prime}$ 均需要估计, 具体可通 过极大似然估计,估计函数如下:

$$
L\left(\beta^{\prime}, \gamma\right)=\lg L=\sum_{i=1} \sum_{j=1} \lg \left(\operatorname{Pr}\left(y_{i} \mid X, \beta^{\prime}, \gamma\right)\right) \cdot I\left(y_{i}=j\right)
$$

式中, $l($.$) 为指示函数,当自变量为真时, 函数值取为 1$, 反之为 0 .

对于解释变量的选择,主要通过相关文献阅读所得,研究中主要选择了以下解释变量:

1) 职工人数:企业规模是影响企业区位选择的重要因素. 企业规模越大,代表了企业需要更多的土地、 供水等要素支撑, 另一方面由于沿湖地区生态环境敏感性较强且土地供给能力有限 ${ }^{[32]}$, 在理性的区位选择 作用下导致规模大的企业向远离太湖的地方选址. 本文用企业的职工人数 $(E P M)^{[31]}$ 代表企业的规模,假设 企业职工人数越多,企业越向远离太湖的区域布局.

2) 开业年份: 随着时间的推移, 政府越来越重视环境保护, 而企业环境意识也会逐渐觉醒 ${ }^{[33]}$, 从而导致 新成立的企业选址时远离太湖布局. 采用企业开业年份 $(Y E A R)$ 作为表征变量,成立的时间越晚,企业越向 远离太湖的区域布局.

3) 是否外资企业:外资企业 (包含港澳台企业)的区位选择表现出双重特质,一方面,外资企业在区位 选择时较少考虑东道国环境保护的影响;另一方面,外资企业在空间选址时,主要是向提供有较多优惠政策 的开发区布局,而开发区在建立的时候会更多地考虑资源环境承载能力,从而导致外资企业向远离太湖的 地区布局. 采用企业是否属于外资企业 $(F R F)$ 来表征,如果是外资企业用 1 表示, 否则为 0.

4) 是否为污染/科技型工业:不同类型企业对环境保护压力的响应程度是不同的,一般来说,污染型工 业污染程度大,应该在远离太湖的区域布局, 而低污染、高附加值的科技型工业是临湖地区主要发展方向, 以替代污染型工业搬迁以后造成的产业真空而靠近太湖地区布局. 分别用是否为污染型工业 $(P L F)$ 和是否 为科技型工业 $(H T F)$ 两个虚拟变量来表示不同类型产业对企业区位选择的影响,假设污染型工业企业向远 离太湖的区域布局而科技型工业企业向临近太湖的地区布局.

\section{2 数据来源与处理}

研究中采用的企业数据来自于 2004 年第一次经济普查企业数据库,包含了企业名称、经济类型、行业 分类、产值、职工人数、地址等信息. 考虑到企业数量样本量较大,研究中根据地址信息采用地址解析 (Geocoding) 方法对数据进行空间化处理, 除去部分地址不清晰和无法识别的企业, 共得到约 $17.8 \times 10^{4}$ 家企业信 息,并根据字段的年份,遴选出 1978 年和 1995 年的企业信息,从而得到 1978、1995 和 2004 年太湖流域工业 企业空间分布数据. 污染型工业采用第一次全国污染源普查确定的重点污染源的分类标准 (2006 年), 而科 技型工业采用国家统计局《高技术产业统计分类目录 (2002)》确定的工业门类, 2004 年有污染型工业企业 $2.3 \times 10^{4}$ 家,科技型工业企业 $1.0 \times 10^{4}$ 家. 


\section{2 结果分析}

\section{1 太湖流域工业企业空间格局及其演化}

本文运用核密度估计的方法计算并比较了太湖流域 1978、1995、2004 年工业企业的空间分布情况 (图 1). 从企业总体分布情况来看, 改革开放以来, 太湖流域工业企业一直表现出明显的空间集聚分布特征, 上 海和苏锡常等平原地区一直是工业企业的主要分布区域. 但是随着时间的推移,这集中分布的格局也呈现

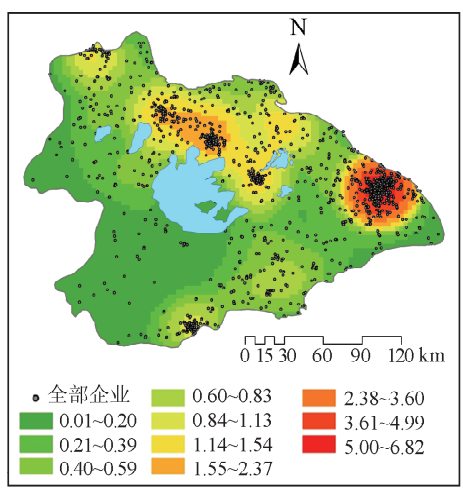

a 1978年全部企业

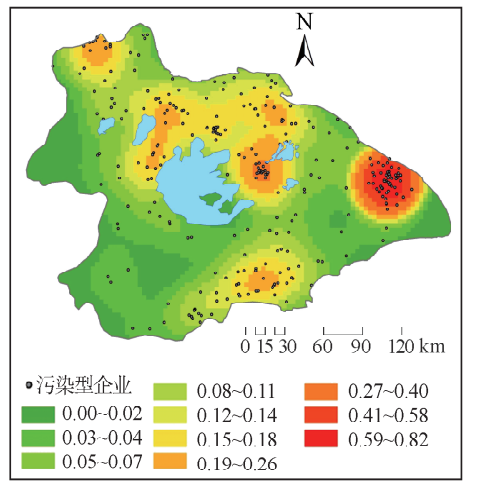

d 1978午污染型企业

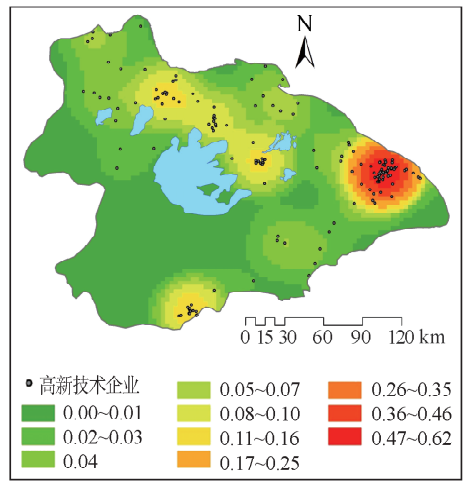

g 1978年高科技企业

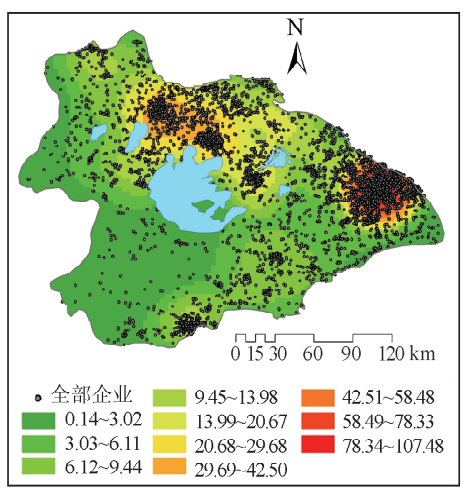

b 1995年全部企业

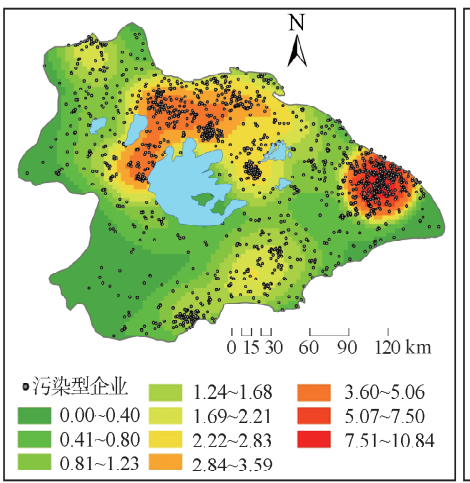

e 1995年污染型企业

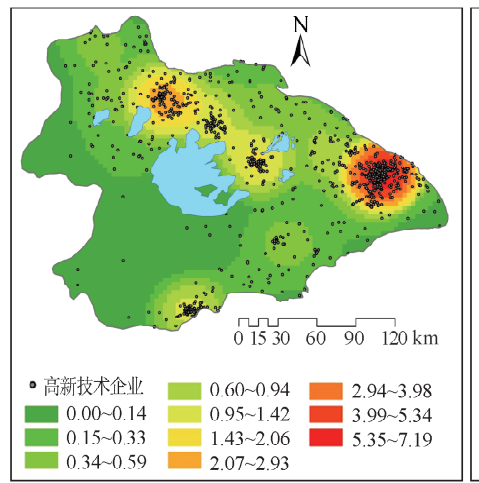

h 1995年高科技企业

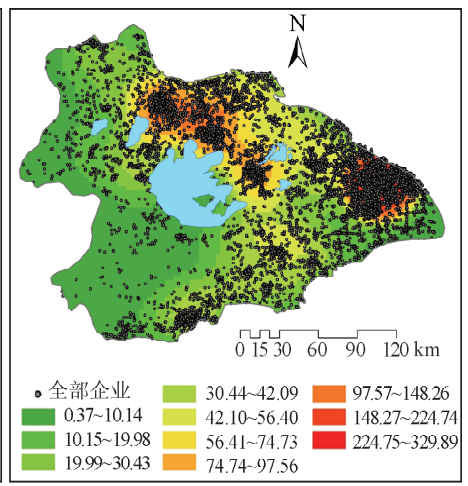

c 2004年全部企业

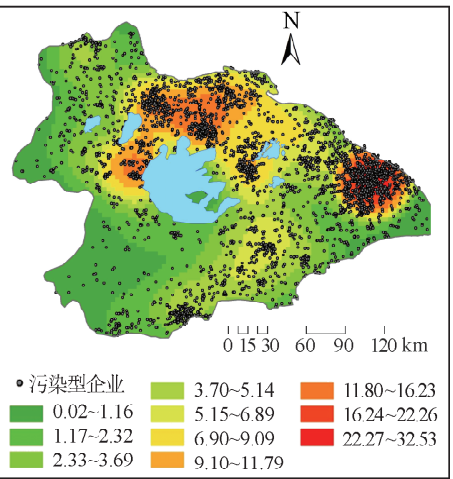

f 2004午污染型企业

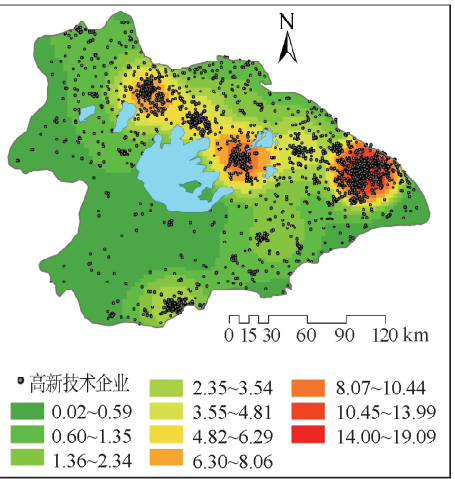

i 2004年高科技企业

图 11978 、1995 和 2004 年太湖流域工业企业核密度估计

Fig. 1 Kerel estimation for industrial firms in Taihu Basin in 1978,1995 and 2004 
出分散化的倾向（图 1),1978 年时企业主要集中在上海、无锡、常州、苏州等城市市区,但是至 2004 年,企业 分布的高值区除上海以外还几乎覆盖了苏锡常所属的全部县区 (图 1a, 图 1c); 另外, 大量的工业企业也开 始向流域西部生态环境较为敏感的山地丘陵地区布局. 良好的工业基础和配套条件是上海和苏锡常地区工 业不断集聚的重要因素. 历史上该地区即手工业发达,鸦片战争后,上海依托优越的区位条件以及对外联系 口岸功能, 迅速成为中国乃至东亚的工业中心, 并带动了无锡、常州等周边城市工业的发展 ${ }^{[34-35]}$, 计划经济 时期,这些城市仍被作为主要的工业基地. 改革开放以后,苏锡常地区乡镇工业依靠上海等大城市国企配套 的需求而得到了蓬勃发展 ${ }^{[17]}, 1990 \mathrm{~s}$ 该地区抓住浦东开发开放和加速改革的重大机遇, 成为国外直接投资 (FDI) 热点. 进一步比较污染型工业和科技型工业的空间分布, 可以发现, 相对于全部工业和科技型工业,污 染型工业企业空间分布要分散得多. 虽然随着时间的推移, 江阴、张家港等环境容量大的沿江地区逐渐成为 污染型工业企业新的集聚区域,但同时污染型工业也向宜兴等太湖的上游地区集聚(图 1e,图 1f). 相对而 言,科技型工业在空间布局上表现出更为明显的集聚特征,1978 年高度集聚在上海市区,杭州、无锡、苏州等 区域中心城市也有少量分布 (图 $1 \mathrm{~g}$ ), 随着时间的推移,科技型工业企业由原来的集聚中心开始向外围地区 扩散,尤其太湖北部沿湖地区成为该类工业扩展的主要区域,形成了沿沪宁线集聚分布格局 (图 1i).

\section{2 流域工业企业区位选择的影响因素}

除去属性值不全的企业样本,代人有序 Probit 模型估计的有效样本是 135749 个. 通过计算自变量间的 相关系数,发现大部分自变量间的相关系数小于 0.1 , 最大的不超过 0.25 , 不存在多重共线性问题, 因此将所 有的自变量同时代人模型, 估计结果见表 $1 . L R$ 统计量为 589.7 , 且 $L R$ 检验结果高度显著, 显示回归方程成 立. 但是模型结果总体上不支持理论预期,即工业企业区位选择时较少考虑太湖保护的要求. 虽然企业规模 $(E P M)$ 对企业区位影响符合理论预期,即规模较大的工业企业相对于较小规模的企业有向远离太湖的区域 分布的趋势, 但是从目前来看, 这种影响还不显著. 企业开业年份 (YEAR) 对工业企业选址的影响是显著的, 但是回归系数的符号为负,与理论预期相反,即后进人的企业仍在向离湖近的地区布局. 外资企业的影响符 合理论预期,且高度显著,表明了外资企业在区位选择时会向远离太湖的开发区布局. 不同产业类型对企业 区位选择的影响是相同的,即无论污染型工业还是科技型工业企业在区位选择上都有向临近太湖区域选址 的倾向.

表 1 太湖流域工业企业区位选择的有序 Probit 模型回归结果

Tab. 1 Regression results of ordered model for industrial firms in Taihu Basin

\begin{tabular}{lcccc}
\hline 变量 & 系数 & 标准误 & $Z$ 值 & $P$ 值 \\
\hline 职工人数 $(E P M)$ & 0.000024 & 0.000015 & 1.574991 & 0.1053 \\
开业年份 $(Y E A R)$ & -0.00605 & 0.000565 & -10.70532 & $<0.0001$ \\
外资企业 $(F R F)$ & 0.092754 & 0.012183 & 7.613497 & $<0.0001$ \\
污染型工业 $(P L F)$ & -0.17151 & 0.016819 & -10.19734 & $<0.0001$ \\
科技型工业 $(H T F)$ & -0.20928 & 0.011013 & -19.00289 & $<0.0001$ \\
\hline 对数似然函数值 & -83026.18 & & $L R$ 统计量 & 589.7 \\
约束对数似然函数值 & -83321.01 & $P$ & $<0.000001$ \\
\hline
\end{tabular}

综合太湖流域工业企业分布格局变化以及企业区位选择的影响因素分析结果, 可进一步发现以下 情况:

1) 以内资为主的小企业是污染型工业在沿湖地区分布的主体. 从核密度估计和有序 Probit 回归结果均 表明污染型工业有向沿湖地区扩展和集聚的趋势,进一步结合企业规模因子和经济类型 (是否外资企业) 的 分析, 可以推测出这些向沿湖地区选址的污染型工业企业主要是小规模的内资企业,这些规模小、环保设施 落后的污染型企业在沿湖地区的不断集中最终引发了太湖蓝藻暴发的危机,这也与 2007 年太湖水危机以 后,太湖流域关闭的企业以小规模的化工企业为主相印证.

2) 环境保护意识淡薄和政府管制措施缺位导致工业企业的无序分布. 从有序 Probit 回归的结果来看, 
目前企业区位选址时较少考虑生态环境的影响,这一方面与现有企业环境保护的意识薄弱有关, 企业在区 位选址的时候更多的考虑经济因素而较少考虑生态社会效益, 另一方面, 也凸显了政府环境管制措施的缺 位, 政府往往将经济增长放在第一位, 而将生态环境保护放在次要位置, 放任了企业的经济理性行为. 在此 情况下,导致无论是污染型工业和科技型工业均呈现出向沿湖地区集中的态势.

\section{3 结论与讨论}

总体而言, 太湖流域工业企业在空间上高度集聚, 主要分布在流域北部工业基础和配套条件较好的上 海及苏锡常地区. 由于环境保护意识淡薄和政府管制措施缺位, 目前太湖环境保护对企业区位选择的作用 仍较为薄弱, 尤其大量以内资为主的小企业呈现向沿湖地区的无序扩散, 这也是诱发 2007 年太湖水危机的 重要原因. 本文研究结果对于太湖流域产业空间布局调整具有一定参考意义. 太湖流域未来工业布局和调 整需要按照长江三角洲地区一体化发展的要求, 加强地区间的专业化与分工合作, 通过加快对沿湖地区污 染型企业的搬迁以及培育科技型工业、服务业等代替现有污染型工业, 同时建立和完善综合考虑生态约束、 开发引导和空间要素的工业发展引导的管制措施 ${ }^{[36]}$ 以及强化政府、公众、企业三方的环境保护意识对流域 环境保护与可持续发展也具有重要意义. 值得注意的是, 太湖沿湖地区在向科技型工业转型的过程中, 也要 严防科技型工业的污染环节在该地区的无序布局.

\section{4 参考文献}

[ 1 ] 王缉慈. 创新的空间:企业集群与区域发展. 北京: 北京大学出版社, 2001.

[ 2 ] Weber A. Theory of the location of industries. Chicago: The University of Chicago Press, 1929.

[ 3 ] Hoover EM. The location of economic activity. New York: McGraw-Hill, 1948.

[ 4 ] Losch A. The economics of location. New Haven: Yale University Press, 1954.

[ 5 ] Isard W. Introduction to regional science. London: Prentice Hall, 1975.

[6] 陈 雯. 空间均衡的经济学分析. 北京: 商务印书馆, 2008.

[ 7 ] Turner RK. Markets and environmental quality. In: Clark GL, Feldman MP, Gertler MP eds. The Oxford handbook of economic geography. New York: Oxford University, 2000.

[ 8 ] Chenery HB. Comparative advantage and development policy. American Economic Review, 1961, 51(1): 18-51.

[ 9 ] Romer PM. The origins of endogenous growth. Journal of Economic Perspectives, 1994, 8(1) : 3-22.

[10] Mehaffey MH, Nash MS, Wade TG et al. Linking land cover and water quality in New York City's water supply watersheds. Environmental Monitoring and Assessment, $2005,107: 29-44$.

[11] Duc TA, Vachaud G, Bonnet MP et al. Experimental investigation and modelling approach of the impact of urban wastewater on a tropical river: A case study of the Nhue River, Hanoi, Viet Nam. Journal of Hydrology, 2007, 334(3/ 4) : 347-358.

[12] Versace VL, Ierodiaconou D, Stagnitti F et al. Regional-scale models for relating land cover to basin surface-water quality using remotely sensed data in a GIS. Environmental Monitoring Assess, 2008, (142) : 171-184.

[13 ] Wei YHD. Regional inequality in China. Progress in Human Geography, 1999, 23(1) : 49-59.

[14] 许 刚, 朱振国, 黄建光等. 无锡市社会经济发展对水环境的影响. 湖泊科学, 2002, 14(2): 166-172.

[15] 谢红涁, 陈 雯. 太湖流域制造业绎水环境演变的影响分析一一苏锡常地区为例. 湖泊科学, 2002, 14(1): 53-59.

[16] 杨龙元, 范成新, 张 路. 太湖典型地区工矿企业废水中主要污染物排放特征研究一一以江苏溧阳市为例. 湖泊 科学, $2003,15(2)$ : 139-146.

[17] Oi JC. Rural China takes off. Berkeley: University of California Press, 1999.

[18] 中国科学院国情分析研究小组. 城市与乡村. 北京: 科学出版社, 1994.

[19] 陈江龙, 陈 雯, 王宜虎等. 太湖地区工业绿色化进程研究一以无锡市为例. 湖泊科学, 2006, 18 (6) : $621-626$.

[20］关劲峤, 黄贤金, 刘晓否等.太湖流域印染业企业环境行为分析. 湖泊科学, 2005, 17(4): 351-355.

[21] 靳晓莉, 高俊峰, 赵广举. 太湖流域近 20 年社会经济发展对水环境影响及发展趋势. 长江流域资源与环境, 
$2006, \mathbf{1 5}(3): 298-302$.

[22] 李伯重. 江南的早期工业化 (1550-1850). 北京: 社会科学文献出版社, 2000.

[23] 陆玉麒, 董 平. 明清时期太湖流域的中心地结构. 地理学报, 2005, 60(4) : 587-596.

[24] 杨大金. 现代中国实业志. 上海: 商务印书馆, 1938.

[25] 曾 刚, 倪 外. 上海浦东发展路径研究. 地域研究与开发, 2009, 28(4) : 9-12.

[26] Wei YHD, Lu Y, Chen W. Globalizing regional development in Sunan, China: Does Suzhou Industrial Park fit a NeoMarshallian district model? Regional Studies, 2009, 43(3) : 409-427.

[27] Wei YHD, Gu CL. Industrial development and spatial structure in Changzhou City, China: The restructuring of the Sunan Model. Urban Geography, 2010, 31(3) : 321-347

[28］杨桂山，王德建等.太湖流域经济发展・水环境・水灾害. 北京: 科学出版社, 2003.

[29] 刘 庄, 郑 刚, 张永春等. 社会经济活动对太湖流域的生态影响分析. 生态与农村环境学报, 2009, 25 (1):2731.

[30］李文涁. 由“太湖水污染事件”到城市规划. 和谐城市规划—-2007 中国城市规划年会论文集, 2007.

[31］贺灿飞, 梁进社，张 华. 北京市外资制造企业的区位分析. 地理学报，2005，60(1)：122-130.

[32］陈 诚, 陈 雯, 王 波. 环太湖地区环境敏感区划定与分区. 经济地理, 2009, 29(1) : 97-101.

[33］袁 丰, 魏也华, 陈 雯等. 苏州市区信息通讯企业空间集聚与新企业选址. 地理学报, 2010, 64(2)：153-163.

[34] 曾 刚, 倪 外. 新中国成立以来上海城市经济发展研究. 经济地理, 2009, 29(11): 1777-1782.

[35] 陈 雯, 向俊波, 汪劲松. 二级城市新经济. 上海: 同济大学出版社, 2006.

[36] 陈 雯, 孙 伟, 禚振坤. 无锡都市区制造业的区位决策影响与适宜性分区. 地理科学进展, 2009, 28(6)： 926-931. 